\title{
Display of the mandibular incisors in older adult patients: orthodontic applications
}

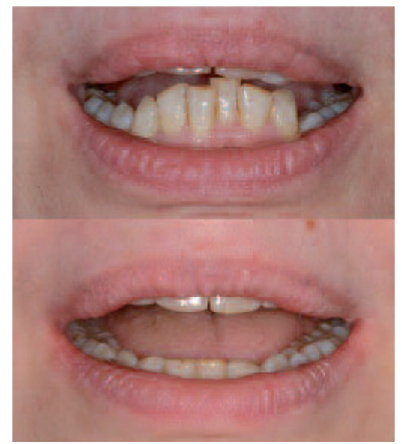

\section{Christine MULLER}

\author{
ABSTRACT

\section{KEY WORDS} \\ Incisors of the lower jaw, \\ Older adult patient, \\ Phonation, \\ Esthetics, \\ Diagnosis.
}

When older adult patients request esthetic enhancement they are mainly concerned about the lower incisors. In fact, for older adult patients, the impact of the mandibular incisors is at least as important as that of the upper jaw incisors on their facial esthetics. This article discusses the importance of specifically documenting this claim and proposes that the diagnostic evaluation of older adult patients should routinely include two specific photos.

\section{1 - INTRODUCTION}

Because society is constantly evolving (esthetic enhancement demands, need for rejuvenation procedures, etc.) more and more older adults are consulting dentists about orthodontic treatment.

In 2009 a study appeared on the esthetic requests of older patients in France ${ }^{6}$. It showed that one third of the patients in this group (older than 55 in this study) would like to change the appearance of their teeth or smile. An in-depth analysis demonstrated that $50 \%$ primarily wanted a straight alignment of the anterior teeth and for them, this request was more important than the color or the shape of their teeth. Clearly, esthetic enhancement for older adults will necessarily involve orthodontic treatment.

Treatment management for older adults calls for orthodontic care that is obviously 
very different from treatment of an adolescent ${ }^{2}$ both from a psychological and technical standpoint (ex. filling in interdental embrasures to achieve a high quality appearance, presence of numerous subgingival issues, permanent retention, etc.), from a biological standpoint (example: the practitioner must differentiate dental movements due to reduced periodontium from those resulting from periodontal disease, etc.) but also from an esthetic standpoint.

This article will focus on esthetic enhancement and will prove that the main point of our discussion is that for older patients, the lower anterior teeth are at least as important as the upper anterior teeth when considering esthetic enhancement. We will describe the clinical orthodontic applications that result from this esthetic parity from the following 4 points:

- modifying soft tissue has an impact on the esthetic importance of the lower anterior teeth;

- phonation and specific esthetic requests;

- an analysis of the inadequacy of traditional phonetic testing;

- specific elements that should be added to the medical records of older adults.

\section{2 - MODIFYING SOFT TISSUE HAS AN IMPACT ON THE ESTHETIC IMPORTANCE OF THE LOWER ANTERIOR TEETH}

The smile is made possible by the combined action of the labial and perioral facial muscles.

A pleasant smile as defined by Fradéani $^{3}$ is a smile that completely reveals the maxillary anterior teeth and approximately $1 \mathrm{~mm}$ of gingival tissue. Over time, soft tissues change anatomically as well as functionally (relaxed physiological tonicity and elasticity of the upper lip and facial muscles relating to the lip and the commissures) that diminish the exposure of the upper teeth and accentuate the exposure of the mandibular teeth.

Increasing exposure of the mandibular teeth coupled with reducing the visibility of the upper teeth, is a major factor in the ageing of the face.

The role of the mandibular incisors in the esthetics of patients 60 years and older, is the same as the role of the maxillary incisors in young patients under $30^{1}$ (Fig. 1).

\section{3 - PHONATION AND ESTHETIC ENHANCEMENT REQUESTS}

The facial esthetics of a person involve more than just the smile. Hence, someone can present a harmonious smile and at the same time have a real esthetic problem when speaking. Generally, patients (with the exception of hair stylists...) only rarely look at themselves in the 


\section{0 ans}

\section{0 ans}

\section{0 ans}

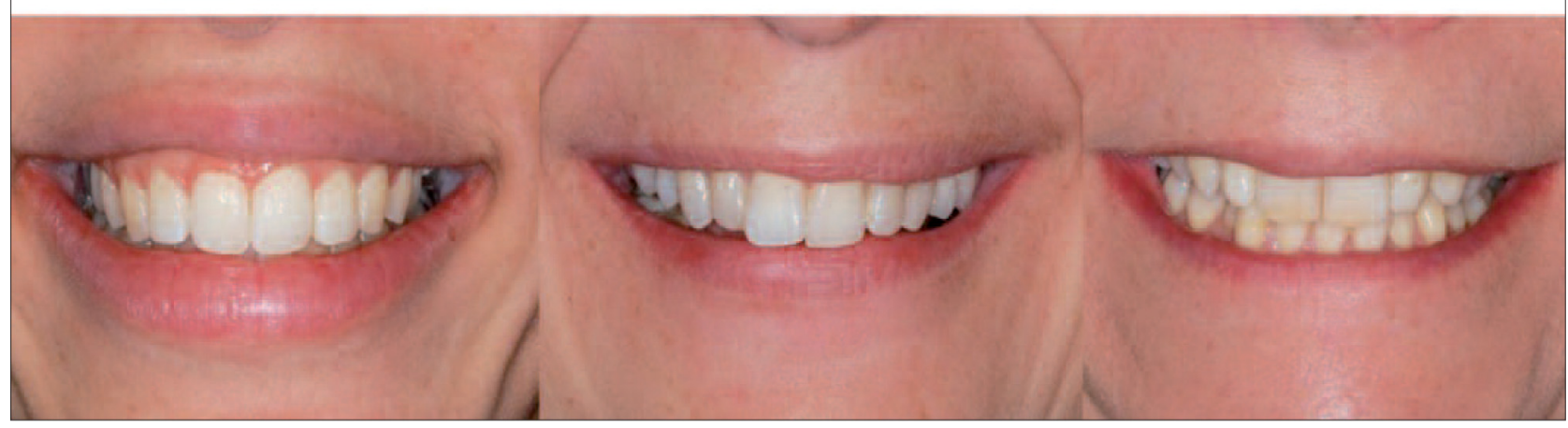

Figure 1

Three smiles show that with age the exposure of the upper incisors gradually diminishes and that this phenomenon is accompanied by an increase in the visibility of the lower incisors. The participation of the upper teeth in the smile reduces the appearance of the mandibular anterior teeth. A wide exposure of the maxillary teeth is a favorable criterion for a beautiful smile. A smile that exposes the mandibular teeth is an ageing smile.

mirror while talking. However, with the advent of cell phone cameras, esthetic problems that show up when we talk are starting to become a frequent request during consultations. "I saw myself in a video...".

The previous statements taken as a whole explain why for older adults who often present with malposed mandibular incisors related to ageing, dental alignment is becoming the pri- mary esthetic request of this age group ${ }^{6}$. This is why practitioners should not take lightly requests involving misalignment of these lower incisors. This esthetic concern is all the more important because patients can hide these unsightly teeth when they smile but, on the other hand, it is harder to exert control and shield these teeth when speaking (Fig. 2).

\section{4 - HOW TO ASSESS THE ROLE OF THE MANDIBULAR INCISORS DURING PHONATION: THE INADEQUACY OF TRADITIONAL PHONETIC TESTING}

Traditional phonetic testing " $M$ " " $F$ " et " $V$ " " $S$ " is an essential aid for diagnosis in dentistry. They yield important information for establishing the length and the position of maxillary anterior prostheses ${ }^{3}$. Nonetheless, these tests do not allow us to assess the involvement of the mandibular incisors because they are especially invisible as demonstrated by the " $F$ " and the " $S$ " on Figure 3.

The clinical crowns of the lower anterior teeth appear when the sound " $A$ " is made".

The directive asked of the patient is therefore to repeat non-stop "mam". 


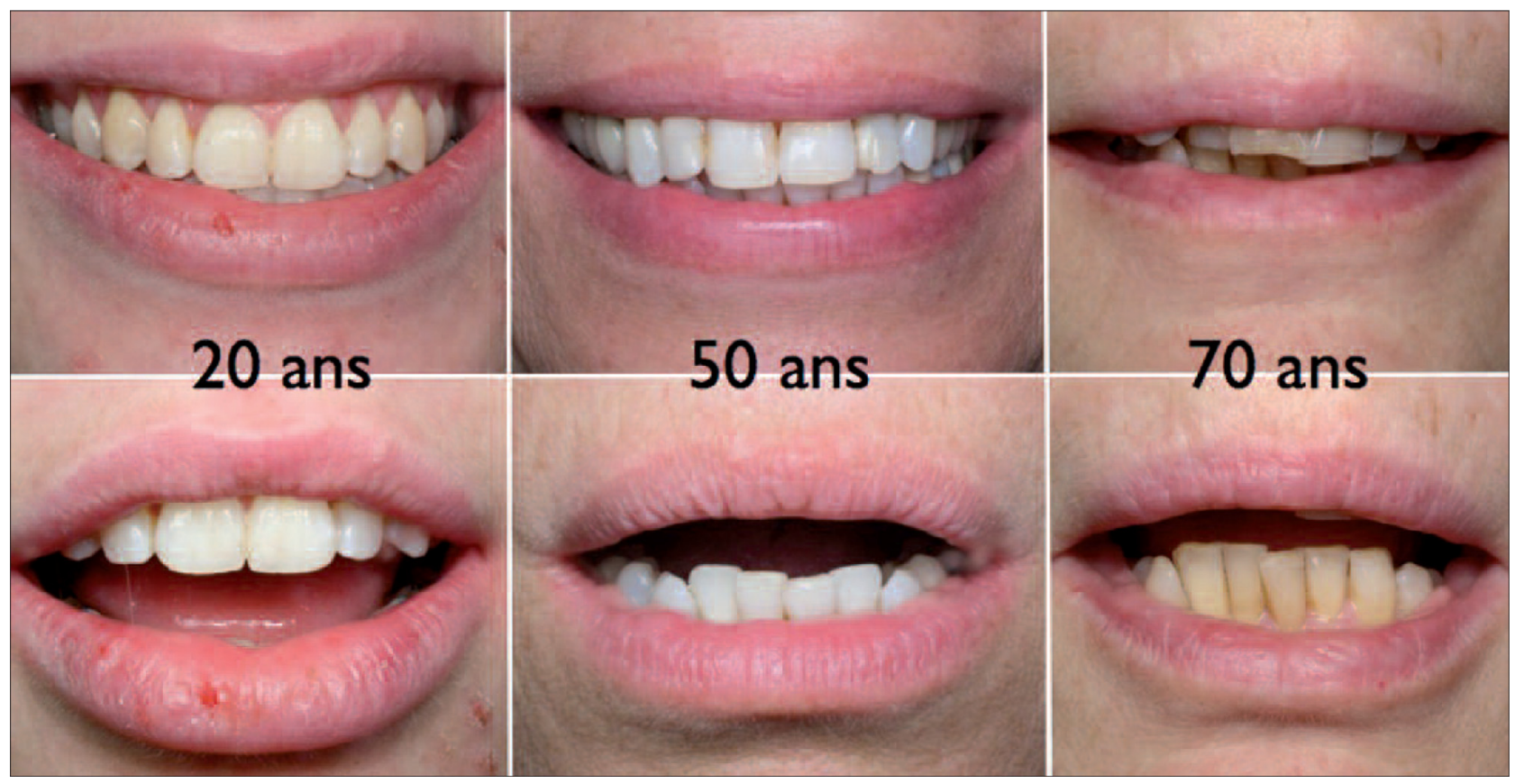

Figure 2

Ageing process and evolution of exposure of the mandibular teeth in the act of smiling (top photos) and while talking (bottom photos). From left to right, the age of the patients is increasing. The 20 year old patient only exposes his maxillary incisors. The 50 year old exposes half the height of the clinical crowns of the mandibular incisors and the 70 year old not only exposes the mandibular teeth but also sometimes shows the gingiva of the lower jaw.

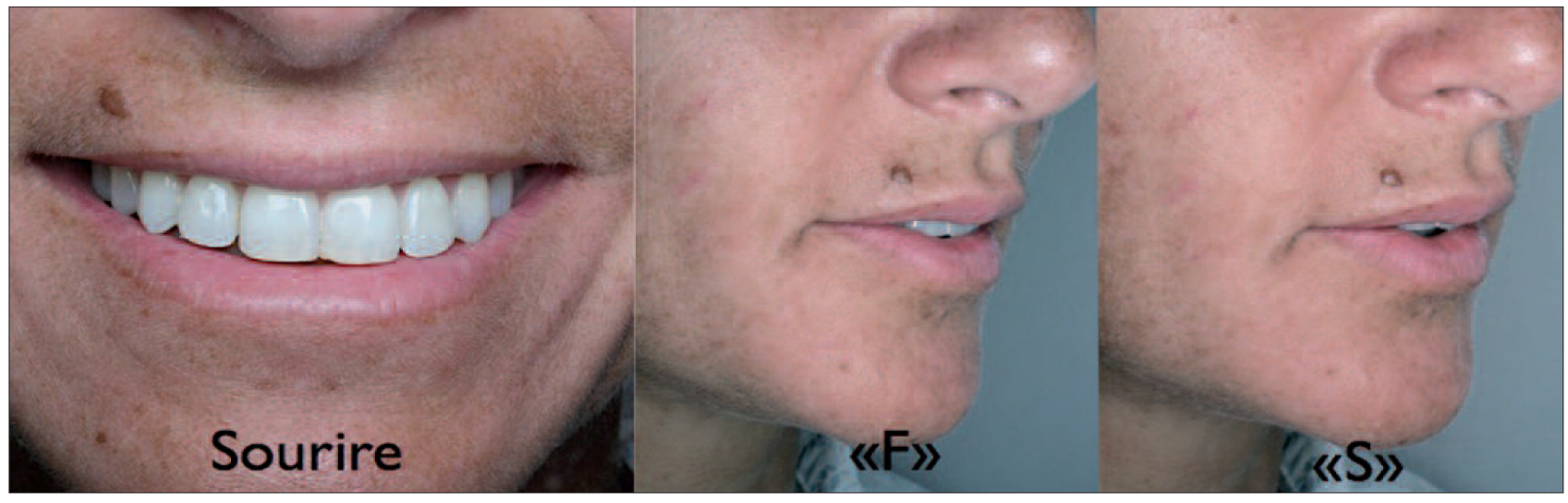

Figure 3

Dental exposure of a 40 year old female while smiling and during traditional phonetic testing that we described earlier.

" $F$ " the length of the upper incisors is considered normal when it lightly touches the inferior vermillon line in the vertical and antero-posterior directions. The mandibular teeth are not visible.

"S" some mandibular movement, slight opening to allow a wide and flat puff of air to pass through for sibilants. The mandibular teeth are barely visible if at all. 


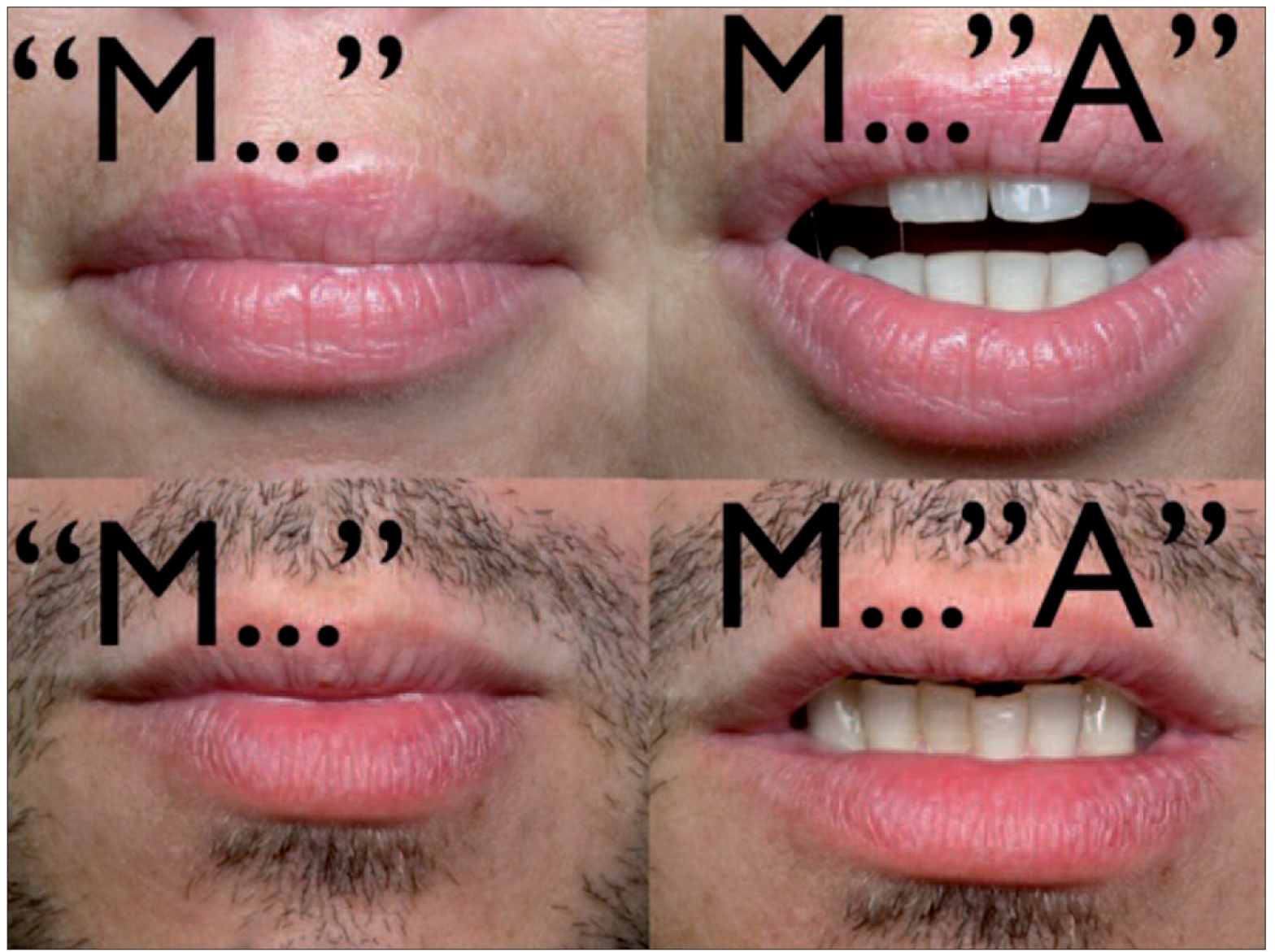

Figure 4

On the photos to the left, the phonetic testing of the sound " $M$ " records the rest position (when the mandible is in the rest position, the arches are separated by a space of 2 to $4 \mathrm{~mm}$ ) that is never completely filled by the teeth: the free space. This observation makes it possible to validate the vertical dimension of occlusion in fabricating a prosthetic device. The teeth are not visible, so the lips are closed.

On the photos to the right, during the phonetic testing of the sound " $A$ " in "Emma" the lips are opening showing the mandibular teeth in the rest position.

Between two repetitions of "mam", the lips are going to open and show the mandibular teeth in the rest position.

To better observe the involvement of the mandibular incisors in a real context, it is recommended that the examiner observe patients while they are sitting engaged in a "friendly" conversation. To record this involvement, the pronunciation of the first name "emma-emma-emma" is a very simple directive, easily done and usually reproducible. When the patient says " $A$ " the examiner takes a picture (Fig. 4). 


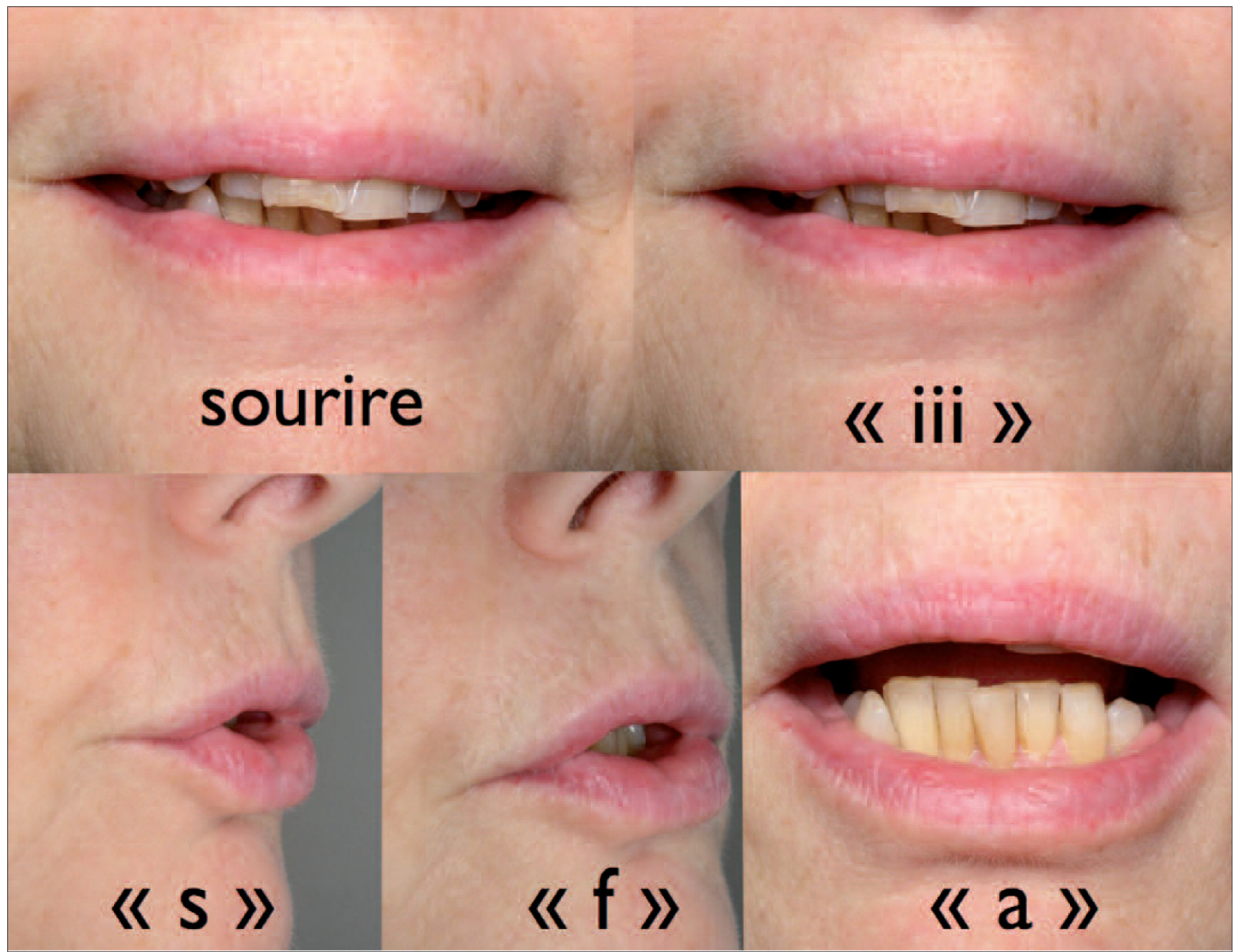

Figure 5

Dental exposure while smiling and phonetic testing. This female patient is 70 years old.

Top photos: smile and phonetic testing " $i$ " showing slight exposure of the maxillary teeth..

Bottom photos: in the far right picture, when making the sound "a", all the clinical crowns of the lower anterior teeth are exposed.

Figure 5 shows the results of the various phonetic tests taken by a 70 year old patient.

The tests confirm that the maxillary teeth are barely exposed with traditional testing when the patient is smiling. However, the involvement of the lower anterior teeth is very conspicuous when the sound " $A$ " is pro- nounced. This test undeniably provides the most data for older patients.

Figure 6 only presents the results for the " $A$ " tests and makes it possible to observe the numerous clinical shapes that are a combination of crowding, protrusion and coronal abrasion. 


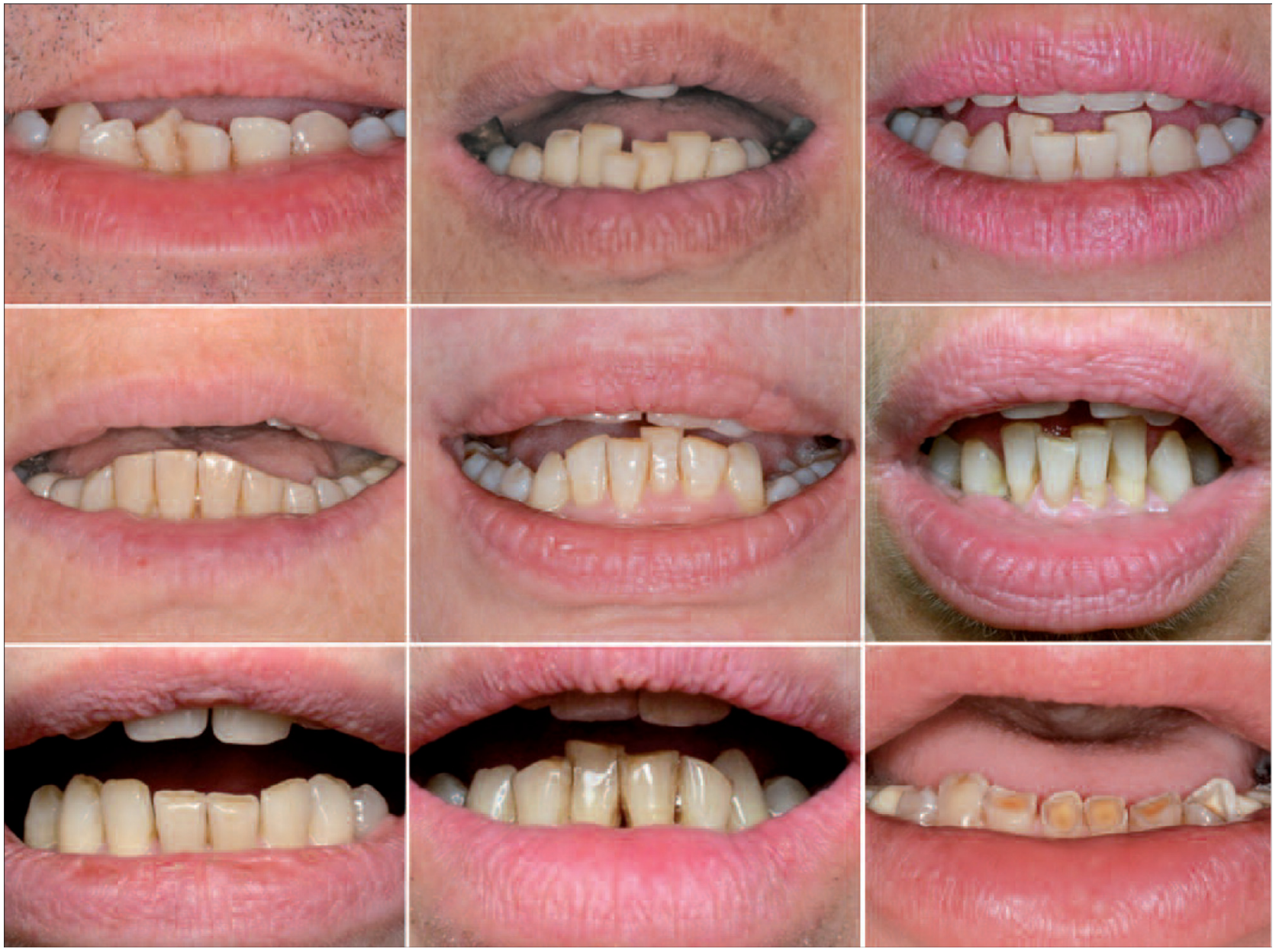

Figure 6

Nine photos of patients whose average age is 60 years. They show dental exposure during the pronunciation of the sound " $A$ " as in "Emma". The upper anterior teeth are barely visible if at all but the lower anterior teeth are conspicuous even to the point of complete exposure of the clinical crowns. Each situation is a combination of crowding, protrusion (we can even see the mandibular gingiva of 2 patients) and abrasion (exposure of the dentin for 3 patients).

\section{5 - HOW TO DOCUMENT THIS PARTICULAR POINT: DATA TO INCLUDE IN OUR CLINICAL RECORDS FOR "OLDER PATIENTS"}

Traditional photographic records include photos of the face, photos of the smile and intraoral photos. The case of the female patient (Fig. 7) demonstrates the inadequacy of the usual films. In fact, in this case, it is essential to document the situation of the lower anteriors by taking two open mouth photos that make it clear why the patient came in for a 


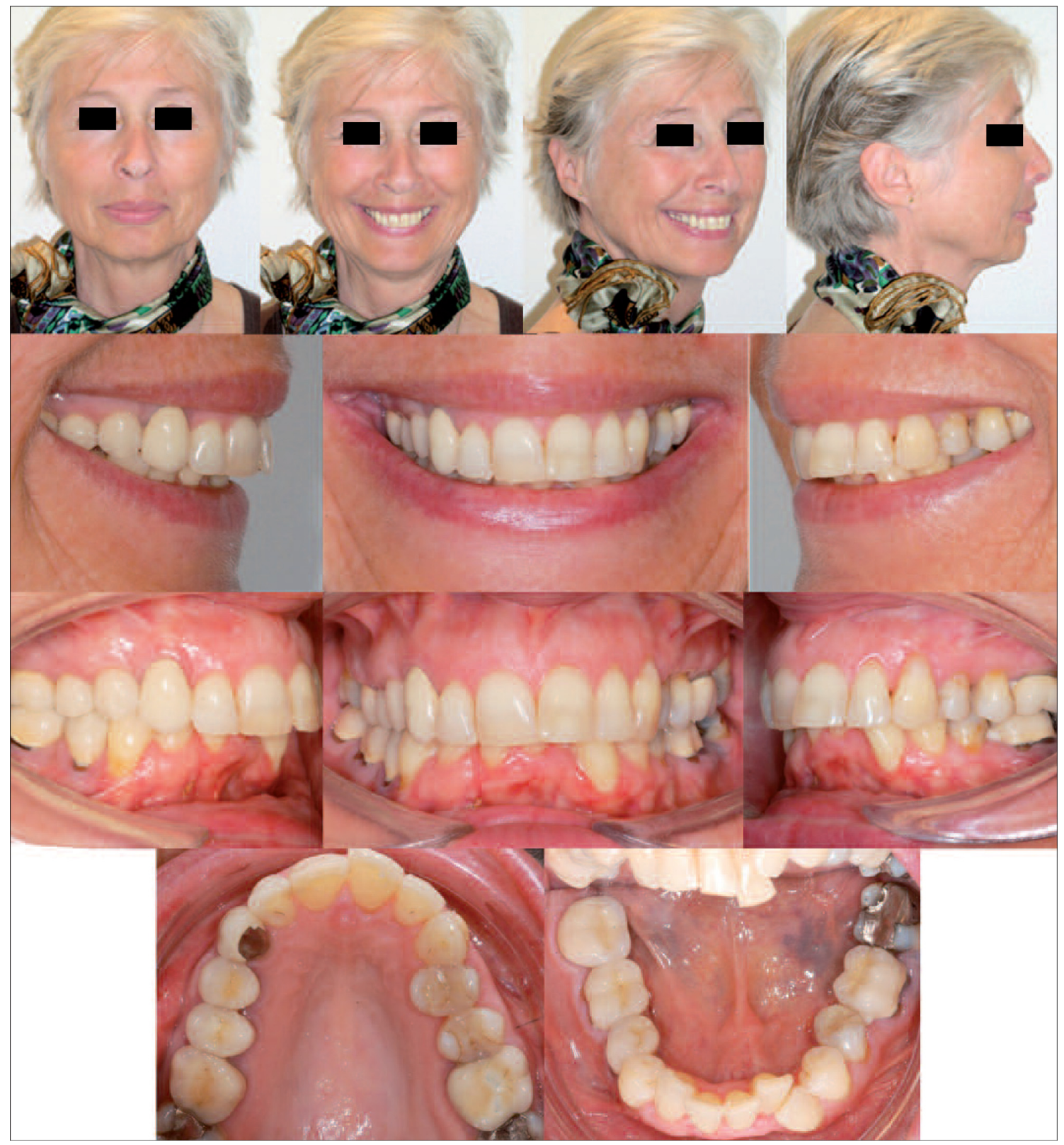

Figure 7

Twelve photos used to document a classic clinical case. 7 extraoral (4 of the face and 3 of the smile) and 5 intraoral photos. 


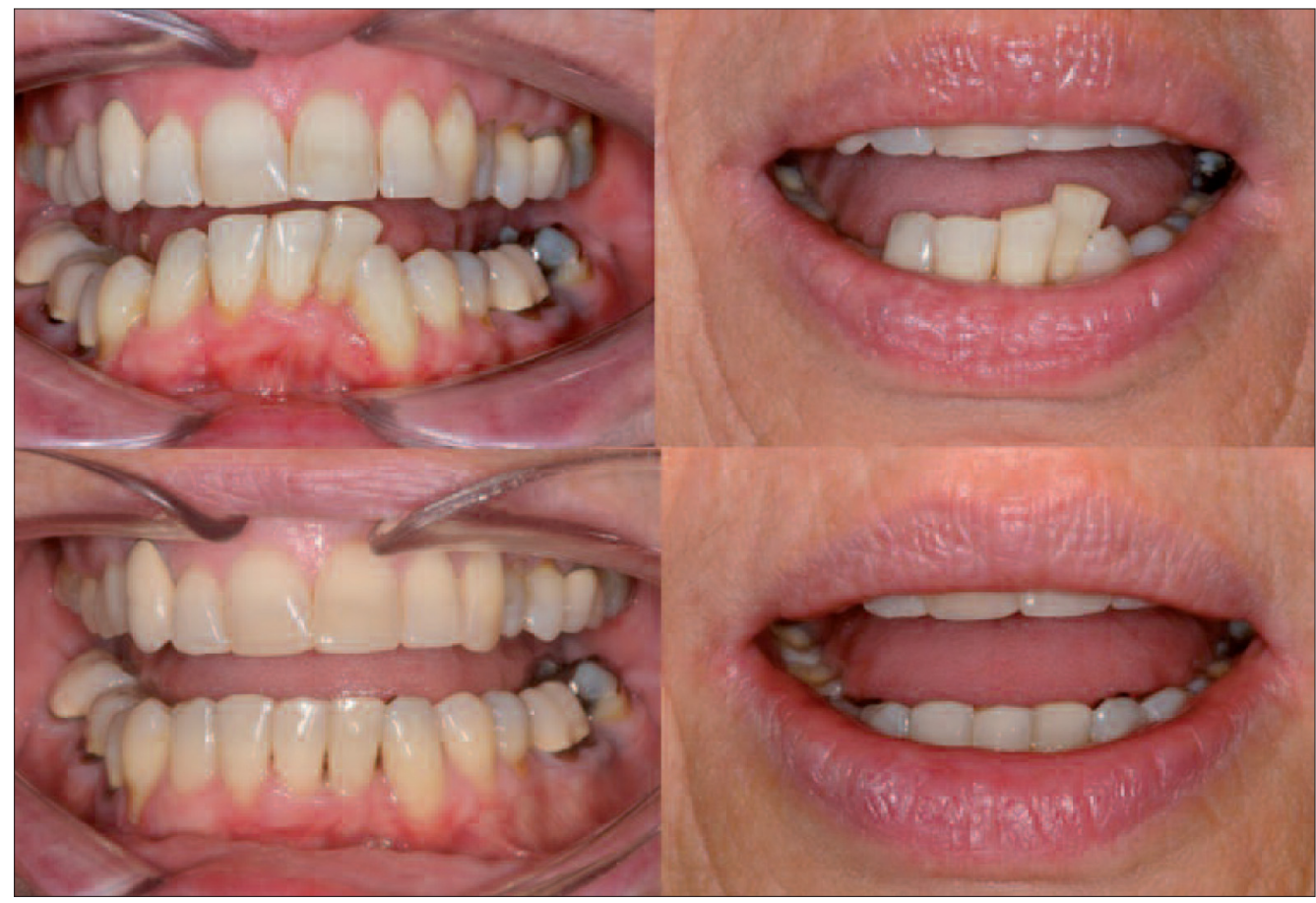

Figure 8

These top views document the lower anteriors. On the left, an intraoral view with a cheek retractor and on the right while pronouncing the sound " $A$ " as in Emma. The bottom views show the results after a period of orthodontic leveling of the lower anteriors (by the way, the lingual device was in place when the picture was taken).

consultation: an extraoral photo for the sound " $A$ " of Emma and an intraoral view (Fig. 8).

These last two views (on the left of the face with open mouth with cheek retractor and on the right - of the face while making the sound "A") will provide obvious and essential data as to why the patient came in for consultation but the photos will also further motivate patients because they are objective proof of how serious the esthetic handicap is. Therefore, the photos validate the patient's request for orthodontic treatment. This validation makes it possible to establish a precise esthetic objective.
Figure 9 shows, in another case, with "before/after" photos, the results after a time of leveling of the lower anteriors. The "before" pictures on the left make it possible for the practitioner to further refine the diagnosis of malocclusion in combination with an esthetic diagnosis (for example: complete exposure of the lower anterior clinical crowns and with a height of $2 \mathrm{~mm}$ of exposed gingiva on average). The photos on the right make it possible to observe and then to assess the result.

Sackstein ${ }^{4,5}$, in a logical extension of our argument, suggests that examiners make a video recording of the phonation of patients during $a$ 


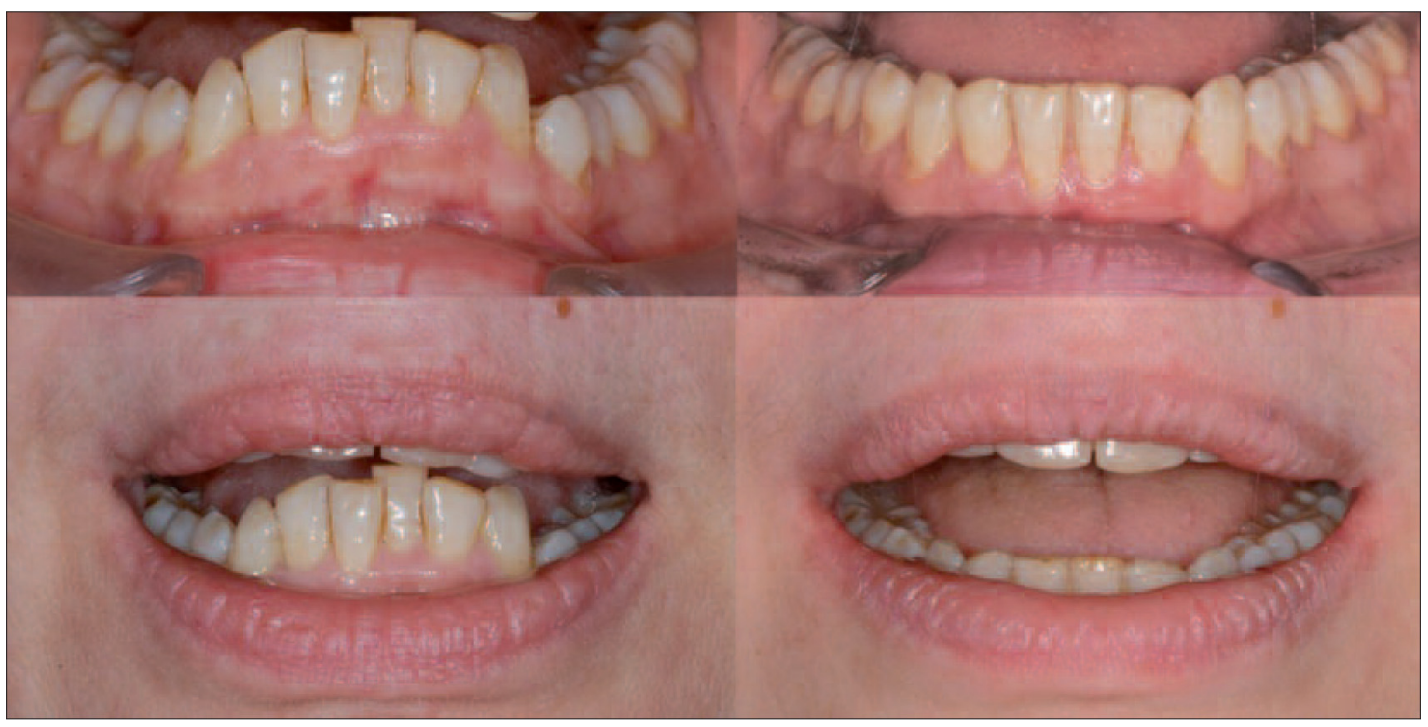

Figure 9

The intraoral photos make it possible to see before and after following a period of orthodontic alignment and leveling of the lower anteriors. The bottom left views show the negative esthetic impact that occurs when the patient is speaking. Notice how rejuvenating the effect of the correction of lower gingival exposure is.

"friendly" conversation which they can then meticulously examine in order to document the exposure of the lower anteriors. Today, researchers are already using this technique which will surely allow for a better understanding of the evolution of malocclusion and the ageing process.

Realistically, we are still not set up in our offices to video and then to store these films in our patient files but this capacity might soon be possible in the near future. We cannot exclude the possibility that a video camera, given all the new technology for photography today, will also be used or might even replace our photographic camera.

This new way of documenting with video could be used day to day in our clinical work for diagnosis and assessment of results but also as a part of a strategy to keep us alert in the long-term for signs of changes in malocclusion.

\section{6 - CONCLUSION}

The older the patients are, the more exposed their lower anteriors are. Exposing the lower anteriors while smiling or speaking is a sign of ageing. As time goes by, our smal- lest teeth have the greatest impact on dental esthetics.

Our awareness of this phenomenon is one of the reasons that led us to suggest that an orthodontic device 
be routinely bonded to the lingual surfaces of the lower anteriors, which is contrary to the commonly held view that orthodontic facial devices are invisible (although it is still true for adolescents).

To specifically and simply document the lower anteriors, two "open mouth" photos are necessary. They have a diagnostic value but they also make it possible to set goals for treatment and to see a good outcome that satisfies the patients (and everyone who knows them) as well as the practitioner who now knows how to respond to their requests.

\section{REFERENCES}

1. Cade RE. The role of the mandibular anterior teeth in complete denture esthetics. $J$ Prosthet Dent 1979;42(4):368-70.

2. Canal P, Salvadori A. (dir.). Orthodontie de l'adulte : rôle de l'orthodontie dans la réhabilitation générale de l'adulte. Paris : Elsevier Masson, 2008.

3. Fradeani $M$. Réhabilitation esthétique en prothèse fixée : analyse esthétique, une approche systématique du traitement prothétique. Paris: Quintessence International, 2007.

4. Sackstein M. A digital video photographic technique for esthetic evaluation of anterior mandibular teeth. J Prosthet Dent 2007;97(4):246-7.

5. Sackstein M. Display of mandibular and maxillary anterior teeth during smiling and speech: age and sex correlations. Int J Prosthodont 2008;21(2):149-51.

6. Wulfman C, Tezenas du Montcel S, Jonas P, Fattouh J, Rignon-Bret C. Aesthetic demand of French senior: a large-scale study. Gerodontology 2010;27(4):266-71.

7. Zachrisson B. Esthetics in tooth display and smile design. In: Nanda R, (ed.). Biomechanics and esthetic strategies in clinical orthodontics. 1st ed. St. Louis: Elsevier, Saunders; 2005:110-30. 